www.jmscr.igmpublication.org

Impact Factor (SJIF): 6.379

Index Copernicus Value: 71.58

ISSN (e)-2347-176x ISSN (p) 2455-0450

crossref DOI: _https://dx.doi.org/10.18535/jmscr/v6i4.101

Journal Of Medical Science And Clinical Research

\title{
Role of Ultrasonography in recognition of malignant potential of thyroid nodules on the basis of their internal composition
}

\author{
Authors \\ Dr Sumanta Kumar Mandal, MBBS MD ${ }^{1}$, Dr Sweta Singh MBBS $^{2}$ \\ ${ }^{1}$ Associate Professor, Dept of Radio-Diagnosis, Bankura Sammilani Medical College and Hospital, Bankura \\ ${ }^{2}$ Post Graduate Trainee, Dept of Radio-Diagnosis, Bankura Sammilani Medical College and Hospital,
} Bankura

\section{Background and Objectives}

Nodular thyroid is a common clinical entity. The optimal diagnostic strategy to evaluate the nodule and differentiate it into benign and malignant, keeping in mind all the associated accompanying features is still a matter of debate. The present study was undertaken to evaluate the diagnostic efficacy of ultrasonography and fine needle aspiration cytology in differentiating benign and malignant thyroid nodules on the basis of composition (solid, cystic or mixed).

\section{Materials and Methods}

A prospective study was carried out in 65 patients of all age groups and both sexes attending the radiology department of Bankura sammilani medical college and hospital, Bankura, during the period Of January 2018 to march 2018. These patients were referred to the department by Department of General Medicine, General Surgery and ENT.

Inclusion criteria-all patients with a palpable neck swelling clinically examined to be thyroidal in origin.
Exclusion Criteria- patients with diffuse neck swelling, ulcerative and fungating neck masses, moribund patients.

All patients thus included in the study, were evaluated by grey scale USG by the linear probe on HD7 Philips machine and colour Doppler and then subjected to FNAC after an informed consent was taken.

Histopathology was done whenever required. The results were then compared.

Statistical analysis was conducted on a master chart created in MS Word and Excel sheet, evaluated by SPSS 17.0. sensitivity, specificity, positive predictive value and negative predictive value were calculated to analyse the diagnostic accuracy of ultrasound and correlating with FNAC/HPE (Fine Needle Aspiration Cytology/ Histopathological Examination), as gold standard. For all statistical tests, $\mathrm{p}<0.005$ was taken to indicate a significant difference.

\section{Observations and Results}

This study was conducted in the Department of Radio-diagnosis of Bankura Sammilani Medical College and Hospital, Bankura.65 patients were included in the study. 
Chart 1-age distribution of patients included in the study

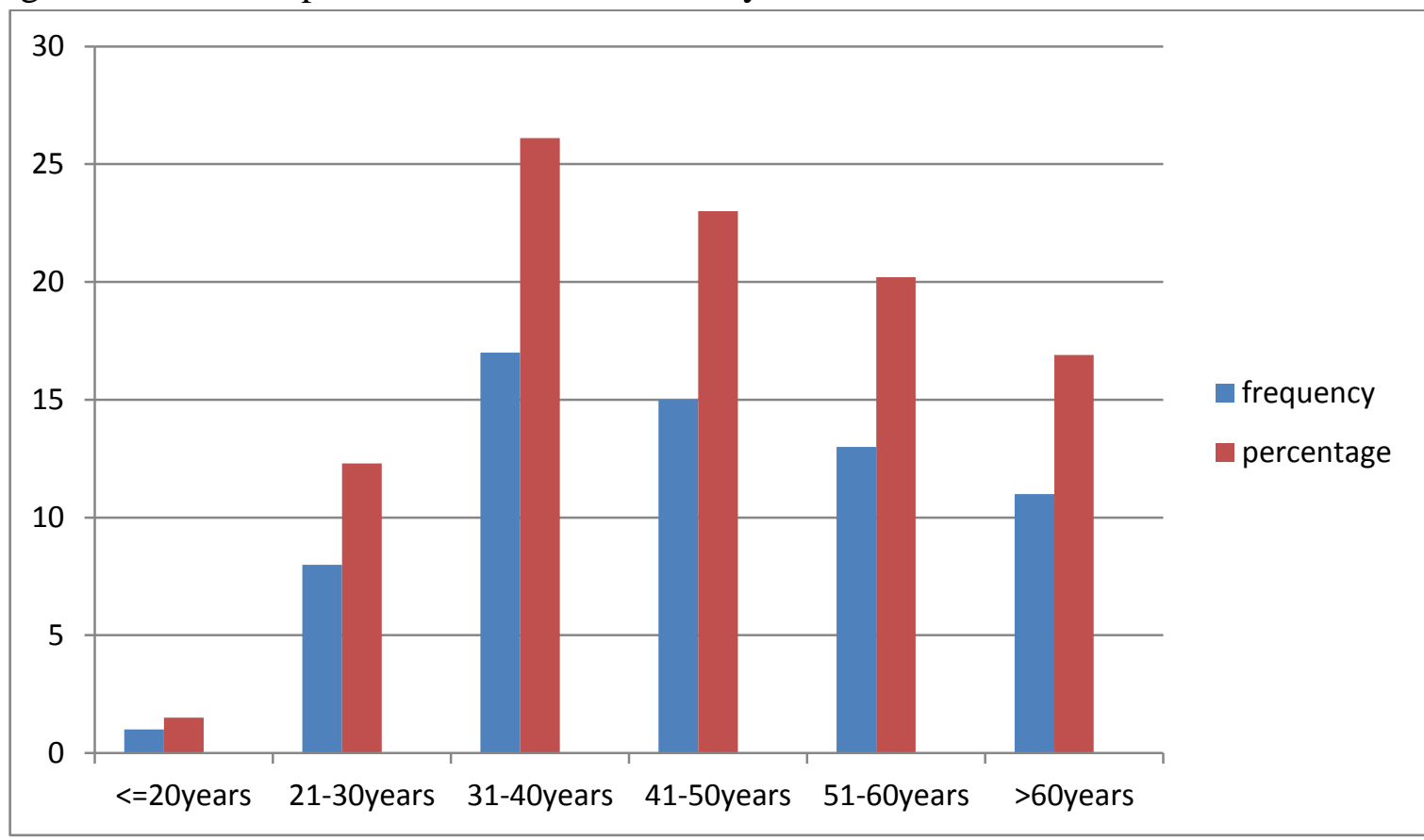

Chart 2- Sex distribution $(n=65)$

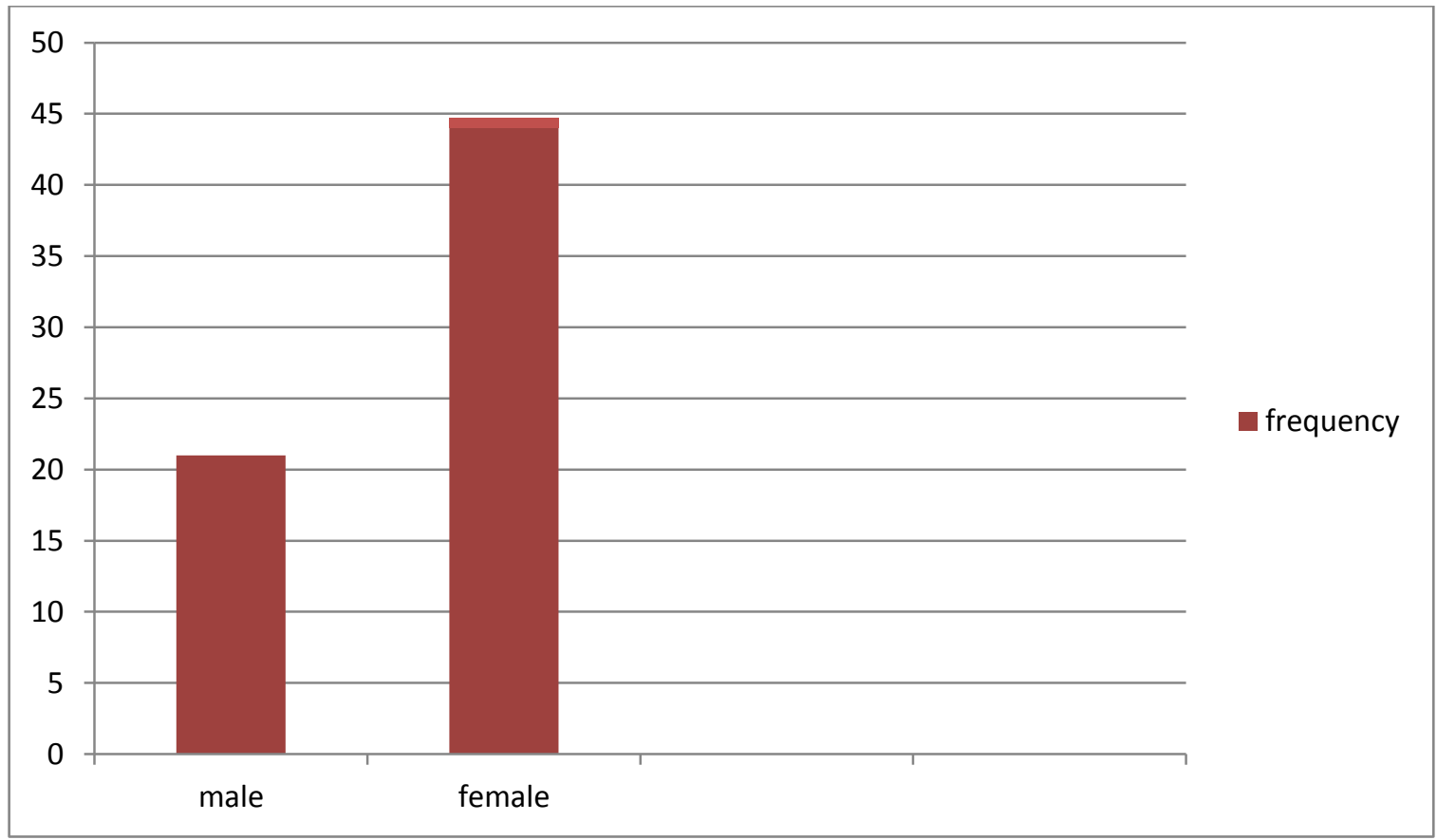

Table 1- Distribution of nodules based on echogenicity

\begin{tabular}{|l|c|c|c|}
\hline Echogenicity & FNAC benign $\%$ & FNAC malignant $\%$ & P value \\
\hline Anechoic & 12 & 0 & 0.322 \\
\hline Heterogeneous & 6 & 6.7 & 1.0 \\
\hline Hypoechoic & 22 & 86.7 & $<0.001$ \\
\hline Hyperechoic & 24 & 0 & 0.05 \\
\hline isoechoic & 36 & 6.7 & 0.049 \\
\hline
\end{tabular}


Chart 3-Distribution depending on echogenicity

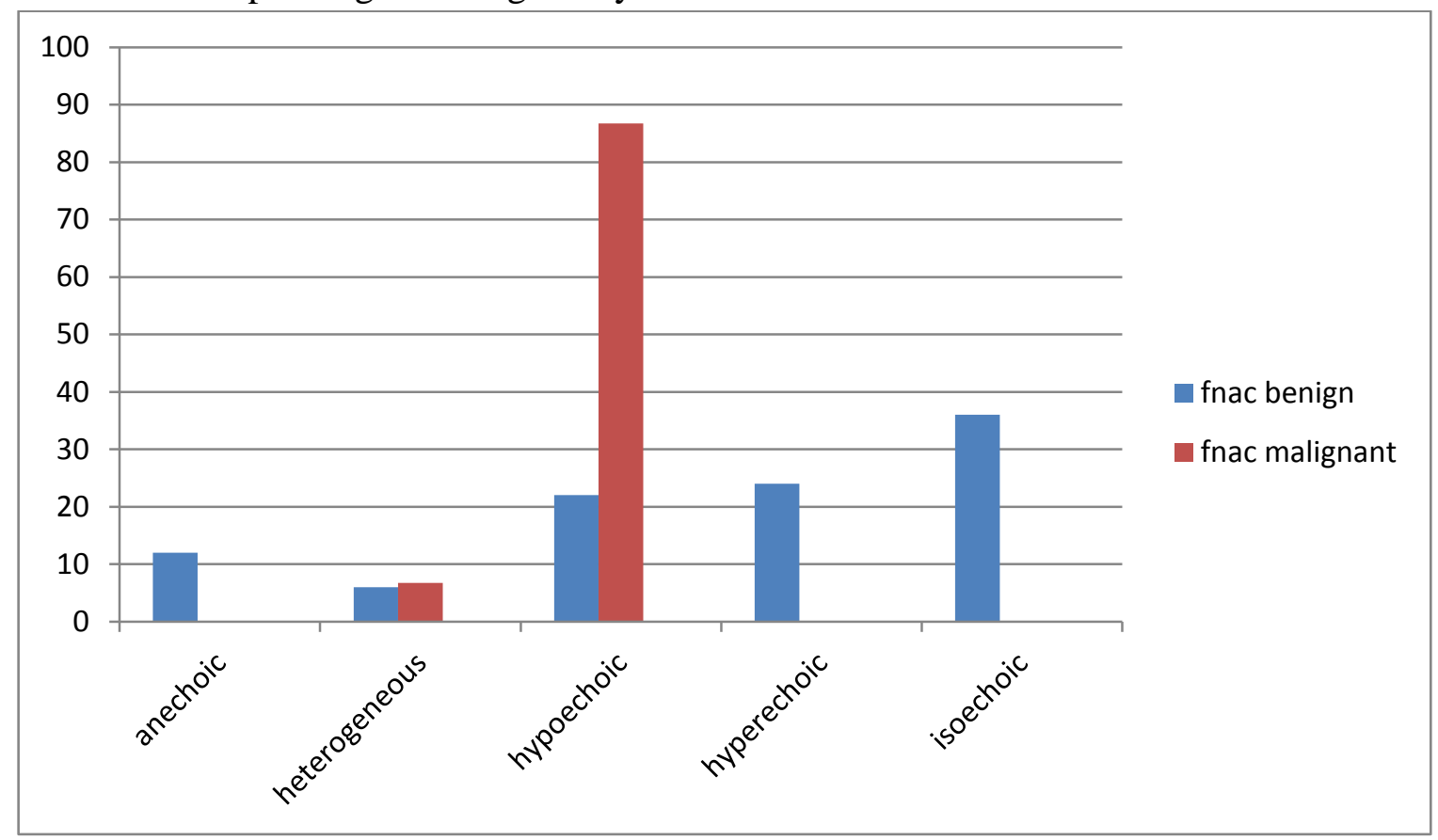

Table 2- Distribution of Thyroid nodules based on internal contents

\begin{tabular}{|l|c|c|c|c|c|}
\hline Internal contents & FNAC & FNAC & FNAC & FNAC & P VALUE \\
\hline & BENIGN & BENIGN & MALIGNANT & MALIGNANT & \\
\hline & FREQUENCY & PERCENTAGE & FREQUENCY & PERCENTAGE & \\
\hline CYSTIC & 5 & 10 & 0 & 0 & 0.70 \\
\hline MIXED & 32 & 64 & 6 & 40 & 0.06 \\
\hline SOLID & 13 & 9 & 60 & 0.015 & \\
\hline
\end{tabular}

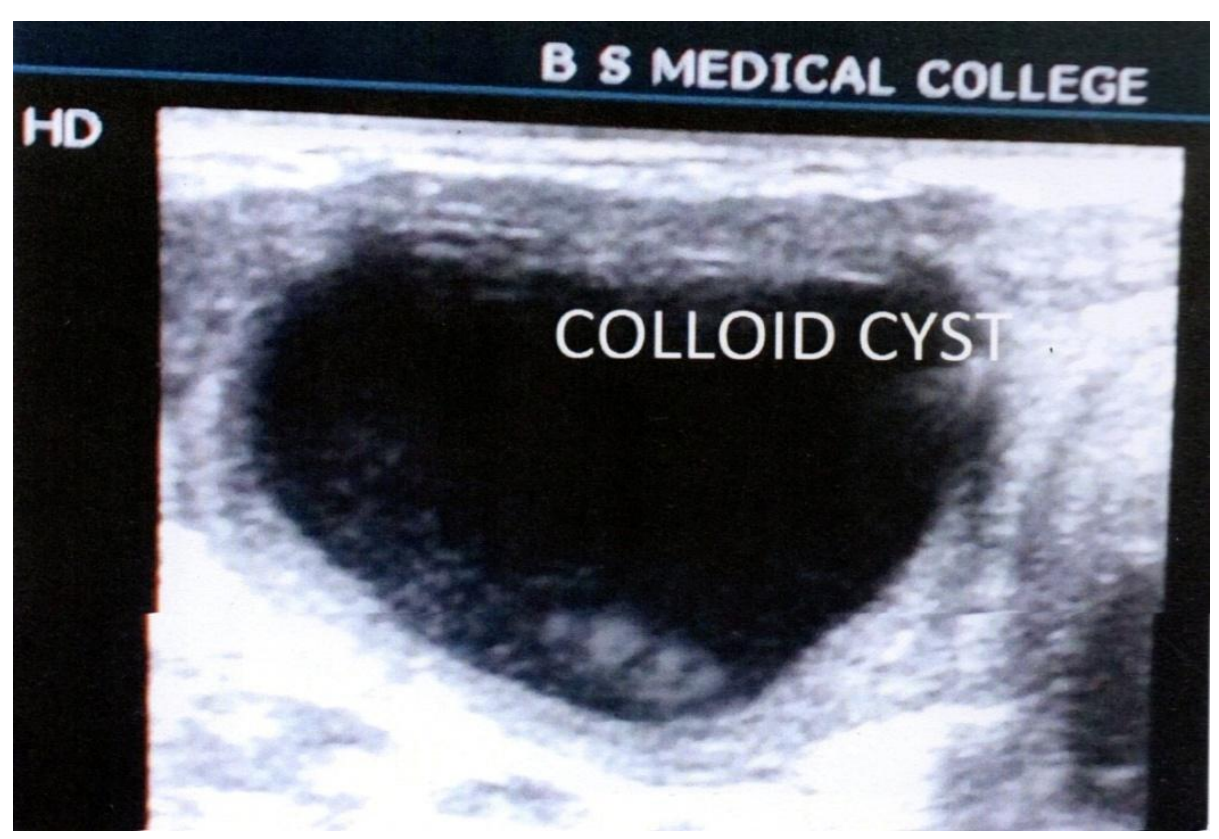

Figure above shows a well defined anechoic cystic Space occupying lesion in right lobe of thyroid. FNACcolloid cyst 


\section{JMSCR Vol||06||Issue||04||Page 615-620||April}

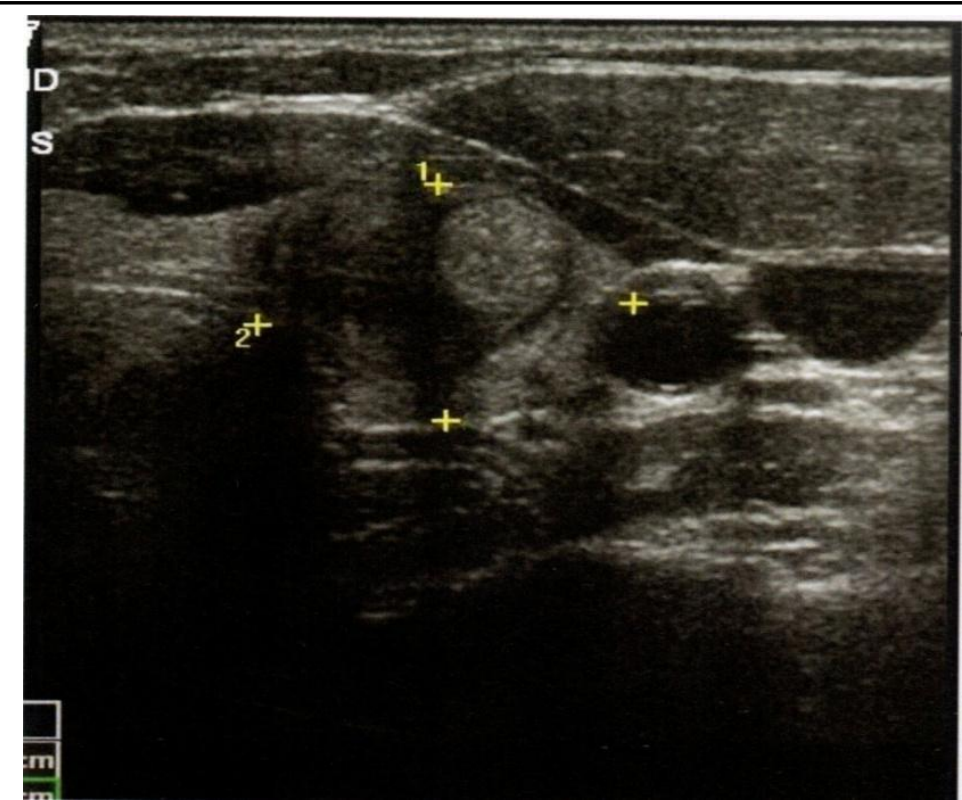

Figure above shows a mixed space occupying lesion with a mural nodule

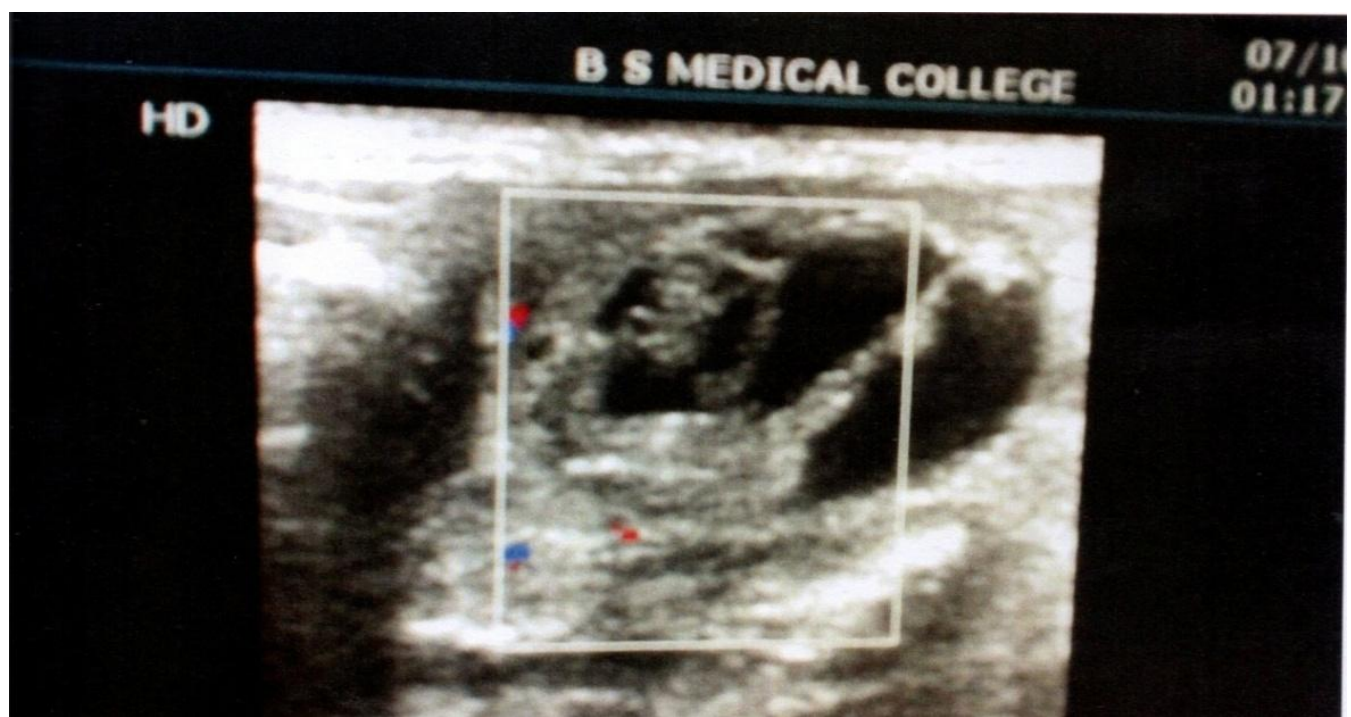

Figure above shows a mixed internal composition space occupying lesion. FNAC-colloid nodule

Chart 4-Distribution depending on internal contents

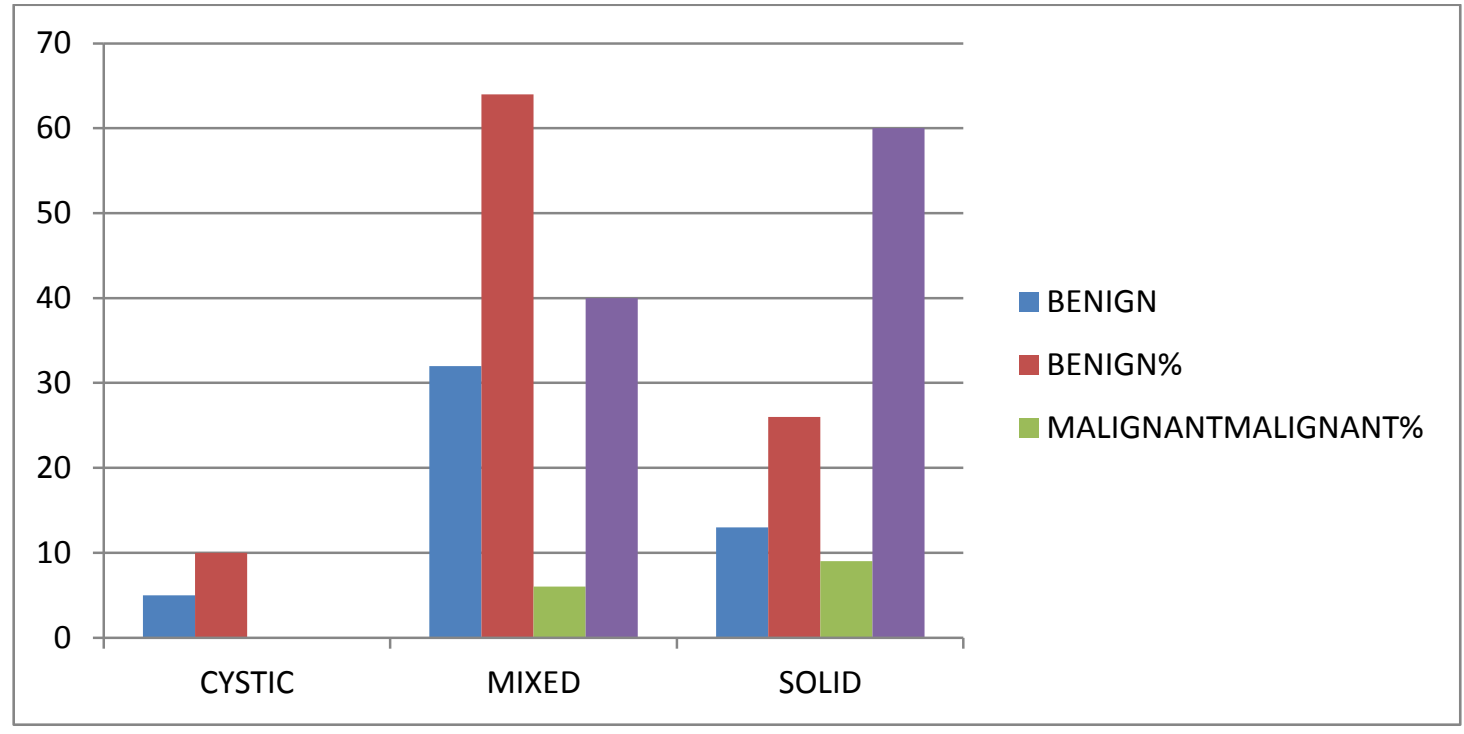


Table 3 Distribution of thyroid nodules based on calcification

\begin{tabular}{|l|c|c|c|c|c|}
\hline Calcification & Fnac benig & $\%$ & Fnac malignant & $\%$ & P value \\
\hline Absent & 40 & 80 & 8 & 53.3 & 0.039 \\
\hline Macro & 5 & 10 & 1 & 6.7 & 1.0 \\
\hline Micro & 5 & 10 & 6 & 40 & 0.007 \\
\hline
\end{tabular}

Chart 5-showing distribution on basis of calcification within nodules

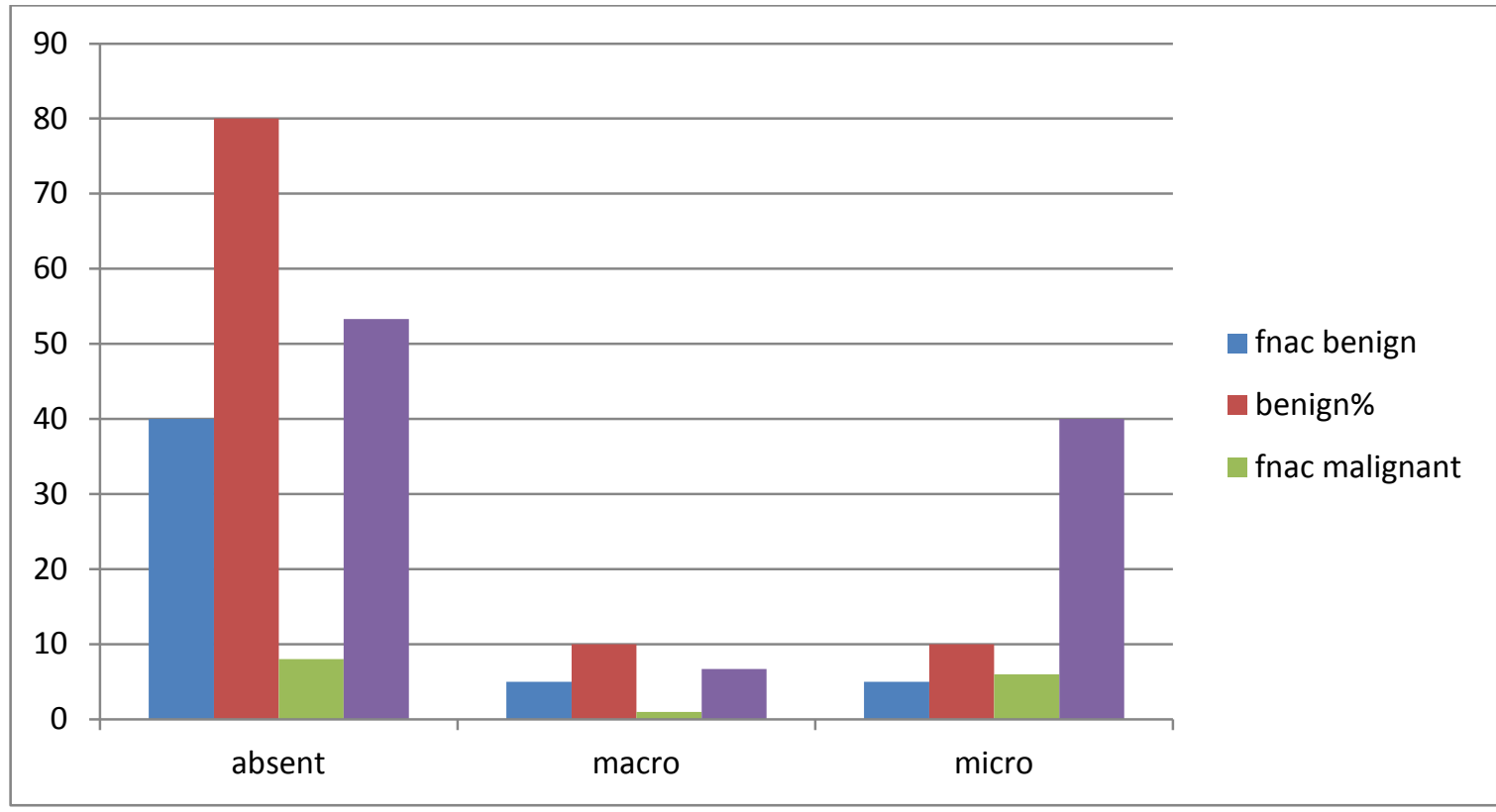

Table 4-Diagnostic accuracy of Duplex ultrasound features for internal composition of malignant nodules

\begin{tabular}{|l|c|c|c|c|c|}
\hline USG features & Sensitivity\% & Specificity\% & $\begin{array}{c}\text { Positive predictive } \\
\text { value } \%\end{array}$ & $\begin{array}{c}\text { Negative } \\
\text { predictive value\% }\end{array}$ & Accuracy \\
\hline Solid & 60 & 74 & 40.9 & 86 & 70.8 \\
\hline Hypoechoic & 86.7 & 76 & 52 & 95 & 78.5 \\
\hline microcalcification & 40 & 90 & 54.5 & 83.3 & 68 \\
\hline
\end{tabular}

Chart 6-diagnostic accuracy of ultrasound for malignant nodules

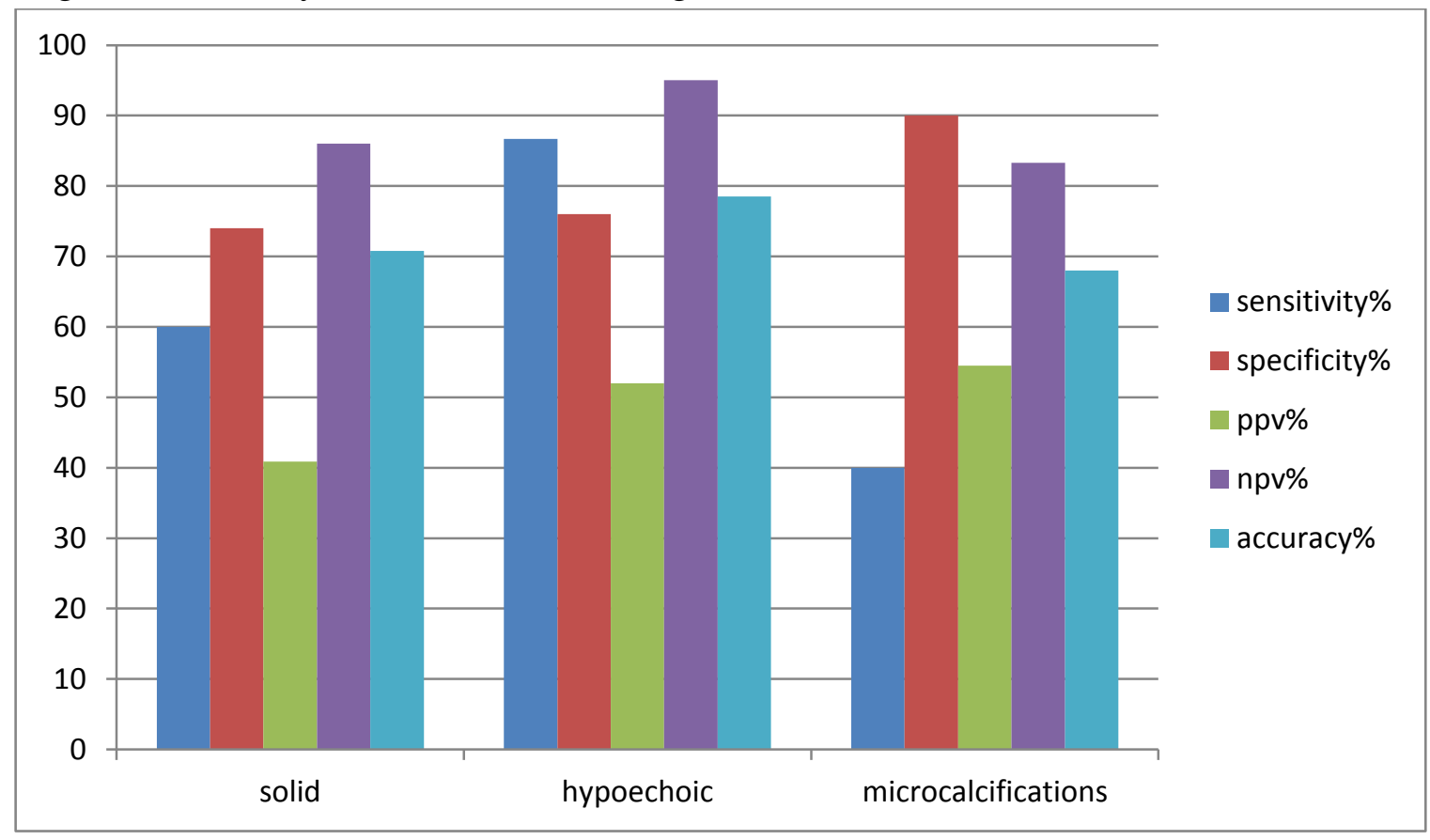


Interpretations and Conclusions-in our study, most of the benign nodules as well as the malignant nodules were predominantly solid or solid-cystic with predominant solid components. thus a predominantly solid component alone cannot be a useful criterion for the differentiation of malignant from benign nodules. The positive predictive value of solid nodules is only $40 \%$ compared to $86 \%$ on negative predictivevalue. out of 50 benign nodules, maximum were isoechoic to the normal glandular parenchyma. Hypoechoic appearance of malignant nodules is significant. presence of micro calcifications in $40 \%$ malignant nodules as compared to $10 \%$ benign nodules is also significant.

\section{Summary}

In our present study, we found that, most of the benign nodules as well as the malignant nodules were predominantly solid or solid-cystic with predominant solid components. thus a predominantly solid component alone cannot be a useful criterion for the differentiation of malignant from benign nodules. A combination of ultrasonographic features as well as pathological correlation is very necessary to increase the diagnostic accuracy and decrease the number of unnecessary invasive interventions in benign cases.

\section{References}

1. Frates MC, Benson CB, Doubilet PM, Cibas ES, Marqusee E. Can color Doppler sonography aid in the prediction of malignancy of thyroid nodules? J Ultrasound Med. 2003;22:127-131. quiz 132-134. [PubMed]

2. Enrico Papini, Rinaldo Guglielmi, Antonio Bianchini, Anna Crescenzi, Silvia Taccogna, Francesco Nardi, Claudio Panunzi, Roberta Rinaldi, Vincenzo Toscano, Claudio M. Pacella; Risk of Malignancy in Nonpalpable Thyroid Nodules: Predictive Value of Ultrasound and Color-Doppler Features, The Journal of Clinical Endocrinology \&
Metabolism, Volume 87, Issue 5, 1 May 2002, Pages 1941-1946.

3. J Ultrasound Med. 2004 Nov;23(11):1455-64. Risk for malignancy of thyroid nodules as assessed by sonographic criteria: the need for biopsy. Iannuccilli JD1, Cronan JJ, Monchik JM.

4. Gupta M, Gupta S, Gupta VB. Correlation of fine needle aspiration cytology with histopathology in the diagnosis of solitary thyroid nodule. J Thyroid Res. 2010; 2010:379051. [PMC free article] [PubMed]

5. Iqbal M, Mehmood Z, Rasul S, Inamullah $\mathrm{H}$, Shah SS, Bokhari I. Carcinoma thyroid in multi and uninodular goiter. J Coll Physicians Surg Pak. 2010;20:310-2. [PubMed]

6. Delbridge L. Solitary thyroid nodule: Current management. ANZ J Surg. 2006;76:3816. [PubMed]

7. Mazzaferri EL. Management of a solitary thyroid nodule. N Engl J Med. 1993;328: 553-9. [PubMed]

8. Kuru B, Gulcelik NE, Gulcelik MA, Dincer $H$. Predictive index for carcinoma of thyroid nodules and its integration with fine-needle aspiration cytology. Head Neck. 2009;31: 856-66. [PubMed] 6

9. Kamran SC, Marqusee E, Kim MI, Frates MC, Ritner J, Peters H, et al. Thyroid nodule size and prediction of cancer. J Clin Endocrinol Metab. 2013;98:564-70. [PubMed]

10. Edino ST, Mohammed AZ, Ochicha O, Malami SA, Yakubu AA. Thyroid cancers in nodular goiters in Kano, Nigeria. Niger J ClinPract. 2010;13:298-300. [PubMed]

11. Rago T, Di Coscio G, Basolo F, Scutari M, Elisei R, Berti P, et al. Combined clinical, thyroid ultrasound and cytological features help to predict thyroid malignancy in follicular and Hupsilonrthle cell thyroid lesions: Results from a series of 505 consecutive patients. 